\title{
Monarquia estatal? Uma análise dos impactos do mito da "Monarquia Unida" na historiografia de Israel e Judá
}

\author{
State Monarchy? An analysis of the impacts of the \\ "United Monarchy" myth on the historiography \\ of Israel and Judah
}

\section{¿Monarquía estatal? Un análisis de los impactos del mito de la "Monarquia Unida" en la historiografía de Israel y Judá}

Josué Berlesi*

Submetido em: 17-6-2021

Aceito em: 16-8-2021
* Universidade Federal do Sul e Sudeste do Pará

Doutor em Teologia

E-mail: josueberlesi@yahoo.com.br

RESUMO

No presente artigo analisamos parte da historiografia sobre a Monarquia Unida de Davi e Salomão bem como os motivos pelos quais a ideia de um reino unido sob o governo dos referidos monarcas se manteve por tanto tempo na pesquisa acadêmica acerca do passado de Israel e Judá. Reflexões sobre metodologia da pesquisa histórica e historiografia serviram a presente análise para verificar o papel do texto bíblico como fonte histórica.

Palavras-chave: Monarquia Unida; historiografia; Bíblia Hebraica.

\begin{abstract}
In this article, we analyze part of the historiography about the United Monarchy of David and Solomon as well as the reasons why the idea of a united kingdom under the rule of those monarchs remained for long time in academic research on the past of Israel and Judah. Historical research methodology and historiography served this analysis to verify the role of the biblical text as a historical source.

Keywords: United Monarchy; historiography; Hebrew Bible.

\section{RESUMEN}

En este artículo analizamos parte de la historiografía acerca de la Monarquía Unida de David y Salomón bien como las razones por las cuales la idea de un reino unido bajo dichos monarcas quedó por tanto tiempo en la investigación académica acerca del pasado de Israel y Judá. Reflexiones sobre metodología histórica e historiografía sirvieron a este análisis para verificar el papel del texto bíblico como fuente histórica.

Palabras clave: Monarquía; historiografía; Biblia Hebrea.
\end{abstract}




\section{Sobre a escrita da História e o caráter da Bíblia como fonte histórica}

A História como disciplina acadêmica é relativamente recente (séc. XIX) enquanto a tentativa de registrar a história remonta ao mundo antigo especialmente se entendemos Heródoto e Tucídides ${ }^{1}$ como os precursores de tal tarefa. Entretanto, para além da contribuição grega o Antigo Oriente Próximo procedeu, de igual modo, a diferentes tentativas de registrar a história muito embora não houvesse aí nesse contexto uma concepção aprimorada de história. No caso dos antigos Israel e Judá sequer existe um termo que defina "história", em todo caso, se tomamos a Bíblia Hebraica como uma fonte para a tentativa de reconstrução da trajetória dessas sociedades com grande facilidade se nota que a percepção de história que permeia seus textos é majoritariamente a seguinte: a história é o palco de atuação do deus Javé. ${ }^{2}$

Javé, aquele que ao longo de um árduo processo conflituoso acaba prevalecendo sobre as demais divindades e estabelecendo-se como único ${ }^{3}$, é um deus que, na concepção dos redatores bíblicos, intervém diretamente na história ora para proteger Israel ora para corrigi-lo permitindo, por exemplo, que certas mazelas atinjam os israelitas. Essa concepção presente nos textos bíblicos reverberou em outros escritos e foi a tônica de muitos manuais "acadêmicos" sobre História de Israel. Ainda no mundo antigo tal concepção é perceptível, por exemplo, nos escritos de Flávio Josefo. O referido pensador judeu, de acordo com Alex Degan, entedia que os flagelos que acometiam seu povo eram parte de uma didática divina uma vez que o próprio Javé castigava os judeus por conta de seus desvios permitindo que a dominação romana os atingisse. Tal modus operandi não era necessariamente uma novidade basta lembrar que Nabucodonosor foi identificado como um instrumento divino por Jeremias, nesse caso Josefo seguia um modelo já conhecido (DEGAN, 2010, p. 307-308).

A noção de intervenção divina na história, como visto, estava dada desde os primeiros escritos que versam sobre o passado de Israel e Judá. Trata-se de uma percepção que vigorou inclusive na academia até boa parte

\footnotetext{
1 Para um debate mais aprimorado sobre a paternidade da escrita da história veja-se: VARGAS, A. Z; MAGALHAES, L. O.; SILVA, M. A. O. Heródoto e Tucidides: história e tradição. Vitória da Conquista: Edições UESB, 2016.

2 Como bem se nota, por exemplo, no livro de Daniel quando mesmo em um cenário em que os servos de Javé encontram-se exilados o próprio Javé ainda detém o controle da história. Veja-se: HARRIS, R. Laird; ARCHER JR., Gleason L.; WALTKE, Bruce K. (orgs.), 1998, p. 1718.

3 Um bom panorama desse processo pode ser visto na obra de RÖMER, T. $A$ origem de Javé: o Deus de Israel e seu nome. São Paulo: Paulus, 2016.
} 
do século passado. Nesse sentido, Dianne Banks destaca que tal percepção explicitamente visível nas obras de importantes investigadores da história de Israel e Judá contribuiu para que o estudo acadêmico de tais temáticas fosse efetivamente afastado dos departamentos de História. De fato, o "antigo Israel" resultou como um órfão acadêmico em meio a comunidade de historiadores o que não ocorreu com as demais sociedades que habitaram o Antigo Oriente Próximo. A pesquisa sobre o tema em questão figurou por longo tempo como um monopólio dos departamentos de Teologia ${ }^{4}$ onde a noção de intervenção divina na história não encontrava maiores resistências. Dentre outros casos Banks se refere ao trabalho de Martin Noth para quem não só a ação divina na trajetória humana era possível como também a Bíblia figurava como uma fonte histórica autêntica (BANKS, 2006, p. 234).

A inexistência de reflexões pertinentes ao fazer historiográfico afetou demasiadamente a produção acadêmica acerca das sociedades em tela. Entretanto é importante que se diga que a pesquisa histórica não é monopólio dos historiadores e historiadoras profissionais. Desde que observados princípios basilares da pesquisa acadêmica, a investigação do passado pode e tem sido feita por profissionais de outras áreas. A esse respeito destaca Carlile Lanzieri Junior:

[...] a existência de narrativas históricas alternativas produzidas por não historiadores não é um problema em si. Na verdade, é saudável e democrático que esse domínio não seja um direito único a ser exercido por esses profissionais a empunhar os seus diplomas. O problema se dá quando essas narrativas alternativas tentam se impor como verdades reveladas a estabelecer um sentido único para o passado [...]. (LANZIERI JUNIOR, 2021, p. 45).

Tais palavras de Lanzieri Junior servem para demonstrar o que ocorreu (e ainda ocorre?) com a historiografia não especializada sobre o tema ao qual estamos nos referindo. Em grande medida, a produção dos manuais de "História de Israel" absorveu a tese de que essa sociedade era distinta de seus vizinhos no contexto do antigo Levante por figurar como um "povo eleito" escolhido e conduzido por seu deus particular. Com isso os referidos manuais mortificavam uma das premissas básicas da pesquisa histórica, qual seja: a história é fruto exclusivo da ação humana de modo que não está sujeita a nenhum tipo de intervenção divina. A permanência de tal concepção (intervenção divina) por longo tempo nas pesquisas sobre

${ }^{4}$ Com uma contribuição inegável das pesquisas arqueológicas praticadas por conservadores religiosos. A esse respeito, veja-se: CLINE, E. H. Biblical Archaeology: a very short introduction. Oxford: Oxford University Press, 2009. 
Israel e Judá produziu marcas indeléveis, entretanto, contemporaneamente o cenário permite um olhar mais otimista. Se há algumas décadas não havia maiores preocupações com os critérios de pesquisa sobre o referido passado o quadro atual seguramente é outro. A esse respeito Megan Moore e Brad Kelle destacam que desde o final do século XX se observa uma crescente preocupação com a metodologia da pesquisa sobre a chamada "história de Israel”, para além disso há uma atenção igualmente crescente com o próprio fazer historiográfico procedendo a um questionamento sobre o que de fato é a historiografia, quais seus critérios, seus objetivos etc. A ausência de preocupação com essas questões em pesquisas pretéritas contribuiu para formar uma imagem distorcida de Israel na Síria-Palestina no contexto das Idades do Bronze e do Ferro (MOORE; KELLE, 2011, p. 466).

A construção da referida imagem distorcida citada por Moore e Kelle contou indubitavelmente com um uso acrítico do texto bíblico. As narrativas da Bíblia Hebraica foram automaticamente transformadas em relatos autênticos da trajetória de Israel e Judá sem a necessidade de maiores comprovações dos conjuntos de evidências externas ao texto em especial a evidência arqueológica. É interessante notar como esse uso acrítico do texto bíblico se perpetuou por tanto tempo mesmo tendo-se clareza de que a preocupação primária do testemunho religioso preservado na Bíblia não é operar como um livro de História. Tal percepção é ponto pacífico nos departamentos de Teologia, ao menos nos mais progressistas, contudo, isso não impediu que as informações apresentadas no texto bíblico fossem equivocadamente utilizadas na tentativa de reconstrução da trajetória histórica de Israel e Judá. Acerca dessa percepção teológica da narrativa bíblica Milton Schwantes acrescenta:

[...] A História de Israel precisa valer-se dos textos bíblicos como fontes históricas; mas estes textos não se auto-definem como documentos históricos. Em outras palavras: o historiador revira o Primeiro Testamento como se fosse uma coletânea de documentos; mas os autores bíblicos criaram seus textos como testemunhos da ação de Deus, não como fontes para a historiografia atual [...]. (SCHWANTES, 2008, p. 12-13).

A informação dada por Schwantes foi amplamente discutida especialmente quanto a validade do texto bíblico como fonte histórica. Independente da questão acerca da contaminação ideológica do texto bíblico, o que queremos enfatizar é o caráter secundário da Bíblia como fonte para a tarefa historiográfica. Em primeiro lugar, talvez, seja necessário considerar qual o gênero de história que se pretende elaborar com o auxílio do texto bíblico, nesse aspecto, Emanuel Pfoh destaca que a narrativa bíblica configura fonte secundária para uma história factual, por exemplo, o texto em tela não pode 
ser tomado como fonte primária para o estudo da suposta Monarquia Unida pelo simples fato de que sua redação é posterior aos acontecimentos que tenta descrever, ou seja, uma história política de Israel e Judá não pode ter a Bíblia Hebraica como fonte primária talvez essa só o seja para uma história intelectual de períodos bastante posteriores como o caso da época persa, helenística e romana (PFOH, 2015, p. 7-8).

As reflexões de Pfoh apontam para um aspecto fundamental que reside na distância temporal entre a informação presente no texto e a sua efetiva fixação por escrito. De fato, a questão da cronologia bíblica ainda é um debate aberto em meio a comunidade acadêmica ${ }^{5}$ e um consenso parece distante. ${ }^{6}$ De qualquer modo, é importante considerar que a escrita não surge por um mero capricho das sociedades antigas, sua origem, via de regra, está atrelada a sociedades estatais bem constituídas que necessitam de uma burocracia ativa para registrar os atos de governo próprios do funcionamento da máquina estatal. Com isso em mente é sabido que o período da chamada Monarquia Unida não constituiu escrita e muito menos chegou a configurar o estabelecimento de um estado como será possível verificar adiante.

A maior parte da suposta trajetória de Israel e Judá presente na narrativa veterotestamentária é uma elaboração a posteriori. Como exemplo de tal situação Anne Gudme e Ingrid Hjelm sustentam que as versões bíblicas sobre o exílio resultam de criações elaboradas por judeus que não vivenciaram dita experiência, outrossim, trata-se de indivíduos que, no período helenístico, experienciaram a diáspora judaica e, assim, forjaram a narrativa de um exílio forçado no intuito de justificar porque eles próprios não estavam habitando o território prometido aos seus antepassados (GUDME; HJELM, 2015, p. 4).

A denúncia sobre as imprecisões que a Bíblia Hebraica pode conter por conta da distância temporal entre os fatos e a sua fixação por escrito não é necessariamente uma novidade. Adolph Lods, nas primeiras décadas do século XX, já pronunciava-se nessa direção. De acordo com Lods se o exemplo das narrativas patriarcais for tomado como amostra de análise há uma lacuna de mais de mil anos entre os supostos acontecimentos e as fontes que os descrevem e, com base nisso, profere uma provocação ao afirmar, por exemplo, que um historiador probo jamais se lançaria na tarefa de reconstruir a época de Cristo tendo por base relatos produzidos no período de monarcas como S. Luis ou Francisco I (LODS, 1956, p. 202).

\footnotetext{
Para um diálogo recente a esse respeito veja-se o episódio catorze da entrevista de Israel Finkelstein concedida a Matthew J. Adams: Disponível em: https://www.youtube.com/watch?v=SISKe1jv8EY, acesso em 15/06/2021.

6 Em anos recentes a questão ficou ainda mais controversa com a publicação da tese de P. Wajdenbaum que tenta supor a autoria do texto bíblico como obra de um único redator. Veja-se: WAJDENBAUM, P. Argonautas do deserto: análise estrutural da Bíblia Hebraica. São Paulo: Paulus, 2015.
} 
De fato, os apontamentos feitos até então servem para expor o caráter secundário da narrativa bíblica como fonte histórica. O texto da Bíblia Hebraica por não ser contemporâneo aos fatos que descreve não pode ser assumido como fonte primária na tentativa de reconstrução das trajetórias de Israel e Judá. Para além disso, o uso de tal narrativa só seria pertinente caso se pretenda proceder a uma história intelectual dos períodos persa e helenístico como muito bem apontado por Pfoh. Para uma história política, ou melhor, para uma história de instituições como a Monarquia, o texto veterotestamentário revela-se de pouco valor. Para Philip Davies, por exemplo, mesmo a pesquisa arqueológica resultará infrutífera ao se tomar a Bíblia como referencial para identificar um Israel histórico pelo fato de suas páginas terem um conteúdo majoritariamente não factual (DAVIES, 2015, p. 154). Nesse aspecto não é demasiado recordar os alertas de Schwantes referidos acima de acordo com os quais o fito primordial do texto bíblico é atuar como um testemunho religioso e não como um registro de acontecimentos históricos autênticos.

\section{A "Monarquia Unida" como argumento circular}

Apesar das percepções contemporâneas sobre os necessários cuidados com o uso do texto bíblico como fonte histórica, a historiografia sobre Israel e Judá teve como seus alicerces as páginas da Bíblia, ou seja, partia-se dela para encontrar referências externas ao texto que o corroborassem. Nesse sentido, a Monarquia Unida de Davi e Salomão foi entendida como um fato tendo configurado uma monarquia estatal e até mesmo um império.

Henri Cazelles em sua História Política de Israel nos dá um claro exemplo da centralidade da informação bíblica no processo de pesquisa sobre a história antiga de Israel. De acordo com o referido autor determinadas passagens bíblicas servem como prova da administração governamental levada a cabo no período da Monarquia Unida. Na prática, o que se desenvolve é um paralelo com outras sociedades estatais do mundo antigo utilizando o texto bíblico como a referência para o exercício de comparação; entretanto, o que Cazelles e outros pesquisadores desconsideraram em suas análises é o fato de que tais informações presentes na narrativa veterotestamentária não encontram corroboração na evidência material. Nesse sentido, vejamos o que diz o autor:

Salomão foi, portanto, sobretudo um administrador segundo a linha da sabedoria política do Oriente [...] A gerência dessa administração central do palácio e do Templo é garantida por uma administração prefeitural (1RS 4, 7-18) [...] Para formar esses administradores e lhes ensinar não somente a escrever e a contar, mas também a exprimir-se, 
precisava-se de escolas de escribas. A esse título, Salomão foi o iniciador da sabedoria em Israel. Como já o tinham feito anteriormente os príncipes cananeus, Salomão se inspirou não somente nos procedimentos tradicionais vindos da Babilônia para Canaã no tempo da dinastia amorita, mas valeu-se também do modelo egípcio. Certos nomes de escribas são, talvez, egípcios. Disso resultará, na corte de Jerusalém, uma tradição de escribas favorável ao Egito, contra a qual o javista do Pentateuco põe em guarda os crentes, precedendo dessa forma aos profetas. (CAZELLES, 1986, p. 146-48).

Nas palavras de Cazelles referidas acima percebe-se uma descrição parcial do governo de Salomão plenamente compatível com uma monarquia de tipo estatal com a presença de uma administração centralizada, um corpo desenvolvido de burocratas e inclusive uma intensa atividade escrita incluindo escolas para a formação de escribas. Dita descrição estaria em pleno acordo com alguns dos critérios que, segundo Gordon Childe, ${ }^{7}$ caracterizam uma sociedade de tipo estatal. Para além disso a descrição de Cazelles ainda engloba outros elementos que caracterizariam um estado potente tais como relações internacionais e o comércio de longa distância:

Se Salomão se voltou ao Egito no que diz respeito a escribas, voltou-se para os fenícios para suas construções e sobretudo para a edificação do Templo e talvez também para a construção de suas fortalezas de Hazor, Meguido e Gazer cuja arquitetura revela semelhanças. Disso resultaram trocas e um comércio que ia até a formação de verdadeiras companhias para a navegação no mar Vermelho [...] É provavelmente essa empresa, com vistas a Ofir e seu ouro, que trouxe a rainha de Sabá a Jerusalém. Começa, então, a influência comercial de Tiro sobre Israel, desenvolveu-se no século IX, e que só teve felizes consequências. Pelo fato de dominar uma parte do litoral e do acesso ao golfo de Acabá, o país gozou então de prósperos anos, graças a um comércio rentável (1Rs 10,15), especialmente o tráfico de cavalos entre a Cilícia e o Egito [...]. (CAZELLES, 1986, p. 148-49).

Como já referido a análise de Cazelles serve para ilustrar a centralidade da informação bíblica no processo de escrita da História de Israel e Judá, o texto bíblico é definitivamente o protagonista e as demais evidências arqueológicas e epigráficas restam em segundo plano. Entretanto, não só a investigação exegética padeceu desse equívoco metodológico, a investigação arqueológica foi igualmente afetada. A descrição de Cazelles cita três sítios arqueológicos conhecidos, Hazor, Gezer e Megiddo, sendo que a interpretação de determinada estrutura (o portão de seis câmaras) em todos eles foi a responsável por gerar um dos exemplos mais nítidos do uso acrítico do texto bíblico para a interpretação da história antiga de Israel.

\footnotetext{
Para uma discussão mais elaborada sobre a lista de Childe veja-se: CAMPAGNO, 2007, p. 9-11.
} 
Nesse sentido, Yigael Yadin, um dos precursores da arqueologia israelense cometeu igualmente o equívoco de render demasiada atenção a informação bíblica. Yadin converteu-se em uma figura emblemática em Israel por sua atuação em diferentes frentes, além de arqueólogo foi também político e chefe militar (CLINE, 2009, p. 42). Teve destacada atuação no sítio de Hazor comandando na ocasião a primeira escavação arqueológica israelense após a criação do moderno Estado de Israel. Entretanto, Yadin também ficou conhecido por seu equívoco na utilização do versículo bíblico de I Reis 9:15 o qual menciona a atividade construtora de Salomão nos sítios de Hazor, Gezer e Megiddo. Como mencionado por Cazelles os referidos sítios apresentam similaridades em especial no caso da estrutura arquitetônica definida como o "portão de seis câmaras". Uma vez identificadas essas similaridades arquitetônicas e influenciado pela informação do referido versículo bíblico Yadin acreditou ter encontrado a prova material da atividade construtora do rei Salomão. Porém, os avanços da pesquisa arqueológica e o consequente aprimoramento dos métodos laboratoriais de datação conseguiram identificar uma considerável distância cronológica entre as estruturas dos sítios envolvidos não sendo possível atribuí-las ao monarca em questão (FINKELSTEIN, 2008, p. 120). A ausência de zelo de Yadin em verificar se as referidas estruturas pertenciam ao mesmo período seguramente está relacionada à centralidade que o pesquisador em tela atribuía ao texto bíblico.

Os exemplos referidos até o momento permitem entender por que o mito da Monarquia Unida vigorou por tanto tempo nas pesquisas sobre Israel e Judá. Para além da relevância atribuída a narrativa veterotestamentária vigorava igualmente a ausência de reflexão sobre determinados conceitos como é o caso da própria concepção de Estado. Entretanto, existiram importantes exceções e dentre elas as pesquisas de Roland de Vaux. Em sua obra Instituições de Israel no Antigo Testamento, De Vaux dedica um capítulo inteiro a análise da concepção de Estado no intuito de identificar se existiu uma em Israel. O trabalho do mencionado autor situa-se no início da segunda metade do século $\mathrm{XX}$, portanto, o autor operava dentro das concepções vigentes em sua época e teve o mérito de analisar mais profundamente as concepções de Estado no mundo antigo oriental algo incomum em outras obras do mesmo período e mesmo de períodos posteriores. Em sua conclusão, De Vaux firmou o seguinte entendimento:

Não se pode falar, pois, de uma concepção israelita de Estado. A confederação das doze tribos, a realeza de Saul, a de Davi e de Salomão, as dos reinos de Israel e Judá, e a comunidade pós-exílica representam outros tantos regimes diferentes. Pode-se, sem dúvida, ir mais longe e dizer que nunca houve concepção israelita de Estado. Nem a 
confederação das tribos nem a comunidade do retorno constituíam Estados. Entre as duas, a monarquia, com formas variáveis, se manteve durante três séculos com relação às tribos do norte, durante quatro séculos e meio com relação a Judá, mas não é fácil determinar até que ponto suas instituições penetraram e modificaram a mentalidade do povo. Com uma facilidade notável, a comunidade pós-exílica volta ao estilo de vida pré-monárquico, o qual permite supor uma continuidade das instituições ao nível do clã e da cidade. Essa vida municipal é também o único aspecto da vida pública que os textos legislativos consideram. Existe a "lei do rei" de Dt 17.14-20 e o "direito do rei" de 1 Sm 8.11-18; cf. 10.25, mas que em nada se parecem a constituições. Esses textos

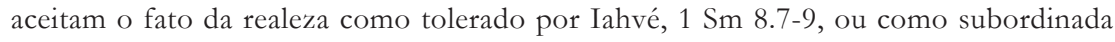
à sua escolha, Dt 17.15, eles alertam contra uma imitação do estrangeiro, $1 \mathrm{Sm} \mathrm{8.5;} \mathrm{Dt}$ 17.14, e contra os males que acarretam tal imitação, 1 Sm 8.11-18; Dt 17.16-17. E nada mais. (DE VAUX, 2004, p. 125).

Há uma considerável distância cronológica entre o trabalho de De Vaux e as investigações que surgiram nos anos finais do século XX, entretanto, mesmo próximo a virada para o século XXI vigorava em determinados meios a percepção de que uma monarquia de tipo estatal era perceptível no registro arqueológico do contexto da Monarquia Unida. Nesse sentido, W. G. Dever igualmente valeu-se dos sítios de Hazor, Gezer e Megiddo para caracterizar a existência de uma organização política de tipo estatal. De acordo com Emanuel Pfoh, a análise levada a cabo por Dever permitia ver nos referidos sítios uma centralização do poder típica da interferência de um Estado observável, por exemplo, pelo tamanho e complexidade arquitetônica dessas localidades, por sua estratificação socioeconômica, pela presença de uma administração política institucionalizada etc Contudo, novamente volta à tona o problema da centralidade da informação bíblica que, do mesmo modo, afetou o trabalho de Dever, pois algumas de suas conclusões só são possíveis se a informação bíblica for automaticamente transformada em informação histórica como é o caso da passagem de 1 Reis 4:7-19 que menciona os supostos prefeitos de Salomão o que nunca foi provado historicamente, logo, deixando-se de lado o versículo em questão resta duvidosa uma pretensa administração política institucionalizada (PFOH, 2009, p. 127).

Ainda na reta final do século $\mathrm{XX}^{8}$ a Nueva Historia de Israel de J. Alberto Soggin insistia no fato de que uma história de Israel minimamente palpável deveria começar pela Monarquia Unida. Nesse sentido, Soggin questionava e afirmava:

Por onde começar uma história de Israel? Em outras palavras: existe uma época a partir da qual comecem os materiais tradicionais a nos oferecer relatos críveis, notí-

\footnotetext{
Estamos trabalhando com a segunda edição de 1999.
} 
cias sobre personagens reais e fatos ocorridos ou ao menos verossímeis, dados sobre acontecimentos importantes no campo econômico e político, junto com suas consequências? [...] Pois bem, durante a última década respondi essa pergunta, indicando como ponto de partida de uma história de Israel o reino unificado de Judá e Israel com Davi e Salomão, reino que incluía também boa parte dos países limítrofes [...] De fato, somente a partir de então começa Israel a existir como entidade não somente étnica (como seria o caso das tribos já instaladas nos próprios territórios, segundo Malamat, 1983), mas também política enquanto que se constitui como Estado. [...] Somente com a criação do Estado, primeiro nacional e logo territorial, se viu Israel diante do problema de sua identidade nacional, do direito de exercer na região uma função determinante, da legitimidade para ser o que com o tempo havia chegado a ser. E não é casualidade que precisamente a partir de então tenhamos as primeiras notícias políticas e os primeiros dados administrativos e econômicos. (SOGGIN, 1999, p. 51-52 - tradução nossa). ${ }^{?}$

Soggin igualmente insiste na ideia do reino unificado sob Davi e Salomão como um Estado plenamente constituído e governado por personagens reais. Quanto a estes aspectos cabe dizer que a evidência arqueológica até então disponível permite concluir que a suposta sede desse Estado, Jerusalém, não possuía a estrutura arquitetônica necessária para operar como a capital de um império. ${ }^{10}$ De igual modo, pouco se pode dizer sobre a historicidade de Davi e Salomão, do primeiro há ao menos uma importante referência extrabíblica na Estela de Tel Dan enquanto o segundo permanece absolutamente invisível fora da Bíblia. Nesse sentido cabe destacar a tentativa de dar vida ao grande monarca bíblico Salomão por meio de uma fraude arqueológica que acabou resultando na prisão do colecionador Oded Golan. ${ }^{11}$

9 Texto original: “¿Por dónde empezar una historia de Israel? En otras palabras: existe una época a partir de la cual empiecen los materiales tradicionales a ofrecernos relatos creíbles, noticias sobre personajes reales y hechos acaecidos o al menos verosímiles, datos sobre acontecimientos importantes en el campo económico y político, junto con sus consecuencias? [...] Pues bien, durante la última década he dado respuesta a esa pregunta, indicando como punto de partida de una historia de Israel el reino unificado de Judá e Israel con David y Salomón, reino que incluía también buena parte de los países limítrofes [...] De hecho, sólo a partir de entonces comienza Israel a existir como entidad no sólo étnica (como sería el caso de las tribus ya instaladas en los propios territorios, según Malamat 1983), sino también política, en cuanto que se constituye como Estado. [...] Sólo con la creación del Estado, primero nacional y luego territorial, se planteó Israel el problema de su identidad nacional, del derecho de ejercer en la región una función determinante, de la legitimidad para ser lo que con el tiempo había llegado a ser. Y no es casualidad que precisamente a partir de entonces tengamos las primeras noticias políticas y los primeros datos administrativos y económicos". (SOGGIN, 1999, p. 51-52).

10 A esse respeito veja-se o episódio quinze da série de entrevistas concedidas por Israel Finkelstein a Matthew J. Adams. Disponível em: https://www.youtube.com/watch?v=uOFZVaMcZsI, acesso em 16/06/2021.

11 Veja-se: https://www1.folha.uol.com.br/fsp/ciencia/fe2307200305.htm, acesso em 16/06/2021. 
Para além da Monarquia Unida algumas pesquisas situadas já no século XXI tentam atribuir a Casa de Omri uma descrição de tipo estatal. ${ }^{12}$ De fato, com a dinastia Omrida se tornam perceptíveis vários indícios de um incremento de complexidade na sociedade do norte de Israel sendo a primeira vez que Israel pode ser percebido como uma entidade sociopolítica (PFOH, 2009, p.139). No período da referida dinastia se evidencia um intercâmbio de itens de luxo, arquitetura urbana mais elaborada e outros itens que estariam de acordo com a descrição de Gordon Childe para caracterizar a presença de uma sociedade de tipo estatal. Do mesmo modo, a Casa de Omri igualmente preserva características de uma sociedade de patronagem e nesse caso, adotando a concepção weberiana de Estado, não poderia operar o monopólio legítimo da coerção, ou seja, não se trataria de uma sociedade estatal. Nesse sentido complementa Pfoh:

De fato, é possível conceber a todos os reinos da Idade do Ferro no Levante a partir de um fator "tribal" que articula sua estrutura interna e fundamenta sua dinâmica sociopolítica (por "tribal" entendemos aqui simplesmente que as relações de parentesco e especialmente a linhagem conformam o fator essencial de organização da sociedade). Recentemente, O. S. LaBianca e R. W. Younker caracterizaram a Ammon, Moab e Edon sob essa descrição onde o "tribalismo" conduz a vida política desses reinos. Igualmente, em uma recente monografia, P. E. Dion caracterizou os reinos arameus da Idade do Ferro dessa mesma maneira. A detecção epigráfica do nome dessas entidades como "Byt + NP" ["Casa de" + Nome pessoal] possui um obvio significado parental (que seja biologicamente fictício ou real não é algo relevante aqui), e o rol dos reis arameus em sua sociedade reflete muitas das características detectáveis em sociedades "tribais", ainda que de uma maneira mais sofisticada. Em suma, não haveria razão para não poder sustentar uma compreensão dos reinos de Israel e Judá sob essa mesma descrição, ao invés de uma caracterização propriamente estatal, a partir do registro arqueológico e epigráfico. (PFOH, 2009, p. 137 - trad. tradução nossa). ${ }^{13}$

12 Veja-se, por exemplo: MENDONÇA, E.V.S. O Primeiro estado de Israel: redescobertas arqueológicas sobre suas origens. São Paulo: Recriar, 2020.

13 Texto original: "En efecto, es posible concebir a todos los reinos de la Edad del Hierro en el Levante a partir de um factor "tribal" que articula su estructura interna y fundamenta su dinámica sociopolítica (por "tribal" entendemos aquí simplemente que las relaciones de parentesco, y especialmente el linaje, conforman el factor esencial de organización de la sociedad). Recientemente, O. S. LaBianca y R. W. Younker han caracterizado a Ammon, Moab, y Edom bajo esta descripción, en donde el "tribalismo" conduce la vida política de estos reinos. Igualmente, en una reciente monografía, P. E. Dion ha caracterizado los reinos arameos de la Edad del Hierro de esta misma manera. La detección epigráfica del nombre de estas entidades como "Byt + NP" ["Casa de" + Nombre Personal] posee un obvio significado parental (que sea biológicamente ficticio o real, no es algo relevante aquí), y el rol de los reyes arameos en su sociedad refleja muchas de las características detectables en las sociedades "tribales", aunque de una manera más sofisticada. En suma, no habría razón para no poder sostener una comprensión de los reinos de Israel y Judá bajo esta misma descripción, antes que con una caracterización propiamente 
Frente ao exposto, não seria apenas a Monarquia Unida que careceu de um Estado plenamente constituído, o mesmo se passou com a Casa de Omri muito mais próxima a uma sociedade de parentesco do que a uma sociedade de tipo estatal. Em todo caso, os exemplos trazidos até então demonstram como o mito da Monarquia Unida vigorou por tanto tempo nas pesquisas sobre a história de Israel e Judá, seguramente por conta da centralidade atribuída ao texto bíblico no processo de pesquisa. Nesse sentido, tratou-se de um típico caso de argumento circular onde a Bíblia informava sobre o reino unificado de Davi e Salomão sendo que a comprovação de dito reino era atribuída as informações do próprio relato veterotestamentário.

\section{A história de Israel e Judá para além da academia: considerações finais}

Como visto as atualizações nesse campo de investigação caminham com certa morosidade, são necessários muitos anos para que se estabeleçam novos entendimentos. Ademais a história de Israel e Judá decorrente da leitura da Bíblia Hebraica está cristalizada no senso comum razão pela qual a pesquisa acadêmica sobre esse passado necessariamente precisa pensar em estratégias para atingir o grande público e assim transcender o círculo profissional. Não é de hoje que as páginas da Bíblia têm sido utilizadas politicamente, contudo, no Brasil atual tal estratégia tem sido incrementada. Apenas para citar um exemplo recente, em meio a pandemia que assola o Brasil e o mundo, determinada emissora de televisão divulgou em sua programação o versículo 20 do capítulo 10 de Eclesiastes que em sua parte inicial afirmava: "Não critique o governo mesmo em pensamento [...]"14 tal fato, assim entendemos, demonstra a necessidade de abordar essa temática para além da academia, como bem aponta Lanzieri Junior:

Confiamos que pensar em uma História Pública que dialogue com as demandas do grande público não especializado, que não se mostre apenas como uma história do presente, mas também como uma história das questões do presente e de como este invade o passado em nome de ideologias e memórias inventadas [...] esperamos que enfim saibamos ocupar outros e novos espaços além de nossas salas climatizadas e utilizar as novas linguagens que as humanidades digitais estão aos poucos a nos oferecer. De forma complementar, mas não menos importante, que da mesma forma sejamos capazes de

estatal, a partir del registro arqueológico y epigráfico. (PFOH, 2009, p. 137).

14 Veja-se:https://odia.ig.com.br/diversao/televisao/2021/06/6166522-sbt-exibe-versiculo-biblico-que-recomenda-nao-criticar-o-governo-confira.html, acesso em 15/06/2021. 
entender como o conhecimento circula nos diferentes ambientes públicos, sejam eles reais ou virtuais, e intervir nesses mesmos de maneira mais frequente e propositiva e menos formal, aliás, bem menos formal. (LANZIERI JUNIOR, 2021, p. 48).

Para além das necessárias intervenções no sentido da História Pública é necessário acercar-se de um ambiente onde a história de Israel e Judá segue sendo abordada continuamente: as escolas de educação básica. Há uma vasta produção acadêmica sobre o conhecimento histórico escolar e o seu trato por meio dos livros didáticos (BARNABÉ, 2014; BITTENCOURT, 1993; GONÇALVES; SILVA, 2001), no entanto, mesmo considerando as distinções entre o saber histórico escolar e o acadêmico julgamos relevante procurar o diálogo com os autores dos livros didáticos bem como com os docentes da educação básica no intuito de revisar a história em questão e os modos como a mesma tem sido efetivamente ensinada no ambiente escolar. Nutrimos a esperança de que esta seja uma estratégia plausível para um entendimento mais aprimorado do passado aqui referido.

\section{Referências bibliográficas}

BANKS, Dianne. Writing the history of Israel. New York: T\&T Clark International, 2006.

BARNABÉ, Luís Ernesto. De olho no presente: História Antiga e livros didáticos no século XXI. Opsis, v. 14, p. 114-132, 2014.

BITTENCOURT, Circe. Os confrontos de uma disciplina escolar: da história sagrada à profana. Revista Brasileira de História, v. 13, n. 25/26, p. 193-221, 1993.

CAMPAGNO, Marcelo. El origen de los primeros Estados: la revolución urbana en América precolombina. Buenos Aires: Eudeba, 2007.

CAZELLES, Henri. História politica de Israel: desde as origens até Alexandre Magno. São Paulo: Paulus, 1986.

CLINE, Eric. H. Biblical Archaeology: a very short introduction. Oxford: Oxford University Press, 2009.

DAVIES, Philip. R. The history of ancient Israel: a guide for the perplexed. London: T\&T Clark, 2015.

DEGAN, Alex. Josefo exegeta: história e memória. Revista de História, São Paulo, v. 162, p. 295-310, 2010.

DE VAUX, Roland. Instituições de Israel no Antigo Testamento. São Paulo: Vida Nova, 2004.

FINKELSTEIN, Israel. Una actualización de la Cronología Baja: Arqueología, Historia y Biblia. Antiguo Oriente, Buenos Aires, v. 6, p. 115-136, 2008.

GONÇALVES, Ana. T. M.; SILVA, Gilvan. V. Algumas reflexões sobre os conteúdos de História Antiga nos livros didáticos brasileiros. História \& Ensino, Londrina, v. 7, p. 123 $142,2001$. 
GUDME, Anne K.H.; HJELM, Ingrid. Myths of exile: history and metaphor in the Hebrew Bible. London: Routledge, 2015.

HARRIS, R. Laird; ARCHER JR., Gleason L.; WALTKE, Bruce K. (orgs.). Dicionário Internacional de teologia do Antigo Testamento. São Paulo: Vida Nova, 1998.

LANZIERI JUNIOR, Carlile. Cavaleiros de cola, papel e plástico: sobre os usos do passado medieval na contemporaneidade. Campinas: D7 Editora, 2021.

LODS, Adolphe. Israel: desde los orígenes hasta mediados del siglo VIII (a. de C). Trad. Vicente Clavel. México: Unión Tipográfica Editorial Hispano Americana, 1956.

MENDONÇA, Elcio. V. S. O Primeiro estado de Israel: redescobertas arqueológicas sobre suas origens. São Paulo: Recriar, 2020.

MOORE, Megan. B.; KELLE, Brad. E. Biblical history and Israel's past. the changing study of the Bible and History. Grand Rapids, MI: Eerdmans, 2011.

PFOH, Emanuel. ¿Cúando comienza la historia de Israel en la antigua Palestina? Apuntes para una discusión. Barcelona: Historiae, v. 12, p. 1-13, 2015.

PFOH, Emanuel. De tribus, Estados y relaciones de patronazgo: Qué es Israel en la Edad del Hierro II? In: CAMPAGNO, M. Parentesco, patronazgo y Estado en las sociedades antiguas. Buenos Aires: Editorial de la Facultad de Filosofía y Letras Universidad de Buenos Aires, 2009.

RÖMER, Thomas. A origem de Javé: o Deus de Israel e seu nome. São Paulo: Paulus, 2016.

SCHWANTES, Milton. História de Israel: local e origens. 3. ed. São Leopoldo: Oikos, 2008.

SOGGIN, Juan. A. Nueva historia de Israel: de los orígenes a Bar Kochba. Bilbao: Editorial Desclée de Brouwer, 1999.

VARGAS, Anderson Zalewski; MAGALHAES, Luiz. Otávio de; SILVA, Maria Aaparecida de Oliveira (orgs.). Heródoto e Tucídides: história e tradição. Vitória da Conquista: Edições UESB, 2016.

WAJDENBAUM, Philippe. Argonautas do deserto: análise estrutural da Bíblia Hebraica. Trad. Elizangela A. Soares. São Paulo: Paulus, 2015. 